\title{
Investigation of the relative biological effectiveness and uniform isobiological killing effects of irradiation with a clinical carbon SOBP beam on DNA repair deficient CHO cells
}

\author{
SHIGEAKI SUNADA ${ }^{1}$, IAN M. CARTWRIGHT ${ }^{2}$, HIROKAZU HIRAKAWA ${ }^{3}$, \\ AKIRA FUJIMORI $^{3}$, MITSURU UESAKA ${ }^{1}$ and TAKAMITSU A. KATO ${ }^{2}$
}

\begin{abstract}
${ }^{1}$ Department of Nuclear Engineering and Management, School of Engineering, The University of Tokyo, Tokyo 113-8656, Japan; ${ }^{2}$ Department of Environmental and Radiological Health Sciences, Colorado State University, Fort Collins, CO 80523,

USA; ${ }^{3}$ Department of Basic Medical Sciences for Radiation Damage, National Institute of Radiological Sciences, National Institutes for Quantum and Radiological Science and Technology, Chiba 263-8555, Japan
\end{abstract}

Received September 12, 2016; Accepted January 6, 2017

DOI: $10.3892 / 01.2017 .6072$

\begin{abstract}
Spread-out Bragg peak (SOBP) C ions have been used clinically in charged particle radiation therapy for years. An SOBP beam consists of various monoenergetic Bragg peaks; however, the biological effect of irradiation with an SOBP beam track has not been well-studied. In order to determine the clinically prospective molecular targets, radiosensitivity to the beam track in DNA repair deficient cell lines was investigated. A total of four distinct Chinese hamster ovary $(\mathrm{CHO})$ cell lines, including CHO10B2 (wild-type), V3 (protein kinase DNA-activated catalytic polypeptide deficient), 51D1 (RAD51 paralog D deficient) and PADR9 [poly(ADP-ribose) polymerase (PARP) deficient], were irradiated with gamma-rays, $\mathrm{C}$ ions $(290 \mathrm{MeV} / \mathrm{n}$ ) and $\mathrm{Fe}$ ions $(500 \mathrm{MeV} / \mathrm{n})$, in order to compare cellular lethality. An OptiCell ${ }^{\mathrm{TM}}$ culture system was used to evaluate the lethality at distinct depths of SOBP C ions. Relative biological effectiveness (RBE) values of $\mathrm{C}$ ions (linear energy transfer (LET), 13 and $70 \mathrm{keV} / \mu \mathrm{m}$ ) and Fe ions (LET, $200 \mathrm{keV} / \mu \mathrm{m}$ ) were calculated from cell survival using colony formation assay with standard cell dishes. All cell lines exhibited similar sensitivity to $70 \mathrm{keV} / \mu \mathrm{m} \mathrm{C}$ ions and $200 \mathrm{keV} /$ $\mu \mathrm{m}$ Fe ions. Furthermore, V3 cells did not exhibit increased sensitivity to high LET $\mathrm{C}$ ions and Fe ions, compared with low LET gamma-rays and $\mathrm{C}$ ions, and 51D1 cells irradiated with $13 \mathrm{keV} / \mu \mathrm{m} \mathrm{C}$ ions exhibited relatively high RBE values among the tested cell lines. Conversely, PADR9 cells exhibited low $\mathrm{RBE}$ values for $13 \mathrm{keV} / \mu \mathrm{m} \mathrm{C}$ ions and high $\mathrm{RBE}$ values for $70 \mathrm{keV} / \mu \mathrm{m} \mathrm{C}$ ions. Obtained using the OptiCell system,
\end{abstract}

Correspondence to: Dr Takamitsu A. Kato, Department of Environmental and Radiological Health Sciences, Colorado State University, 1618 Campus Delivery, Fort Collins, CO 80523, USA E-mail: takamitsu.kato@colostate.edu

Key words: spread-out Bragg peak, Chinese hamster ovary, OptiCell, high linear energy transfer, DNA repair the survival fractions in the SOBP region were uniform for wild-type and PADR9 cells. Conversely, V3 and 51D1 cells exhibited decreased cell death in the distal region of the SOBP. These results indicated that PARP is a more effective target for clinical beam therapy, compared with the non-homologous end joining repair and homologous recombination repair pathways. PARP deficiency may be an optimal target for $\mathrm{C}$ ion therapy and the results of the present study may contribute to the development of a more effective heavy ion radiation therapy.

\section{Introduction}

Heavy ion radiation therapy began in the 1970s in the USA as a more efficient radiation therapy compared with classical $\mathrm{X}$-ray therapy $(1,2)$. Heavy ion therapy is gaining prevalence, and has been increasingly utilized in Japan, China, Germany and Italy $(1,2)$. Heavy ions exhibit three advantageous cancer cell killing characteristics when compared with X-rays. Heavy ions exhibit a more efficient dose distribution in cancer tissues due to the Bragg peak. The phenomenon allows for the majority of the dose to be deposited within the cancer tissues, avoiding unnecessary radiation exposure to normal tissues. In addition, heavy ions form complex DNA lesions within the cell due to the large amount of energy deposited during particle/DNA interactions. Heavy ions are able to produce more complex DNA lesions compared with X-rays and gamma-rays $(1,2)$. Complex DNA damage lesions are more difficult to repair, compared with the simple DNA damage lesions frequently observed following irradiation with X-rays and gamma-rays (3). Furthermore, heavy ions have a low oxygen enhancement ratio (3). Heavy ions are more effective at cell killing under hypoxic conditions when compared with $\mathrm{X}$-rays and protons (4).

Currently, spread-out Bragg peak (SOBP) C ions are used in heavy ion radiation therapy $(1,2)$. An SOBP beam consists of various monoenergetic Bragg peak beams to extend the Bragg peak region to effectively cover the entire cancerous area and lead to tumor cell death (5). SOBP C ions have been 
demonstrated to be effective in the clinic $(1,2)$; however, the biological effect of the beam track has not been well-studied. In particular, the linear energy transfer (LET) values in the SOBP region are increased compared with conventionally used radiation, including $\mathrm{X}$-rays and gamma-rays, and these values increase with the depth of the beam track $(1,2)$. Due to this, the quality of the DNA lesion at each depth point is regarded as being distinct $(1,2)$. It has been reported that high LET irradiation requires distinct DNA repair mechanisms compared with low LET irradiation, and these differences are specifically observed in the two primary DNA double strand breaks (DSB) repair pathways: Homologous recombination (HR) and non-homologous end joining (NHEJ) $(6,7)$. However, the differences between high and low LET irradiation remain to be completely elucidated.

In the present study, the radiosensitivities of four Chinese hamster ovary $(\mathrm{CHO})$ cell lines to SOBP $\mathrm{C}$ ions were evaluated to investigate how assorted DNA repair proteins responded to various LET values, and the subsequent effect on NHEJ, HR and single strand break repair $(8,9)$. The present study utilized the OptiCell ${ }^{\mathrm{TM}}$ system, previously established by the authors $(10,11)$, to investigate the effects of distinct LET-induced radiosensitivities. The OptiCell system enables the biological effect to be perceived at each depth point of the beam path, allowing for a comprehensive analysis of the SOBP beam. It was observed that only the single strand break repair deficient cells demonstrated LET-dependent radiosensitivity in the SOBP region. The results of the present study may affect the future development of heavy ion radiation therapy.

\section{Materials and methods}

Cell culture. The CHO10B2 (wild-type), V3 (protein kinase DNA-activated catalytic polypeptide deficient) (12) and PADR9 [poly(ADP-ribose) polymerase (PARP) deficient] $(13,14)$ cells were donated by Dr Joel Bedford (Colorado State University, Fort Collins, CO, USA). The 51D1 (RAD51 paralog D deficient) cells were donated by Dr Larry Thompson (Lawrence Livermore National Laboratory, Livermore, CA, USA) (15). All cell lines were grown in minimum essential medium $\alpha$ (Wako Pure Chemical Indsutries, Ltd., Osaka, Japan) supplemented with $10 \%(\mathrm{v} / \mathrm{v})$ heat-inactivated fetal bovine serum (Sigma-Aldrich; Merck Millipore, Darmstadt, Germany), and $1 \%$ penicillin, streptomycin and Fungizone solution (antibiotic-antimycotic; Invitrogen; Thermo Fisher Scientific, Inc., Waltham, MA, USA), at $37^{\circ} \mathrm{C}$ in an atmosphere containing $5 \%$ $\mathrm{CO}_{2}$. Exponentially growing log phase cells were used in the present study.

Irradiation. Irradiation with gamma-rays was performed at Colorado State University using a J.L. Shepherd Model Mark I-68 nominal $6000 \mathrm{Ci}{ }^{137} \mathrm{Cs}$ irradiator (J.L. Shepherd and Associates, San Fernando, CA, USA) at room temperature and at a dose rate of $2.5 \mathrm{~Gy} / \mathrm{min}$ (16). Heavy ion irradiation was performed at the National Institute of Radiological Sciences (Chiba, Japan). C ions and Fe ions were accelerated to 290 and $500 \mathrm{MeV} / \mathrm{n}$, respectively, using the Heavy Ion Medical Accelerator in Chiba (HIMAC). Dose rates for $\mathrm{C}$ ions and $\mathrm{Fe}$ ions were set at $1 \mathrm{~Gy} / \mathrm{min}$. $\mathrm{C}$ ions and Fe ions had LET values of 13 and $200 \mathrm{keV} / \mu \mathrm{m}$ upon entrance. For monoenergetic beam irradiation, 13 and $70 \mathrm{keV} / \mu \mathrm{m} \mathrm{C}$ ions, and $200 \mathrm{keV} / \mu \mathrm{m}$ Fe ions, were used. Monoenergetic $\mathrm{C}$ ions with an LET of $70 \mathrm{keV} / \mu \mathrm{m}$ were obtained by Lucite attenuation (17). For OptiCell (Thermo Fisher Scientific, Inc.) irradiation, $\mathrm{C}$ ions were accelerated to $290 \mathrm{MeV} / \mathrm{n}$ initial energy and spread out with a ridge filter to produce an SOBP of width $6 \mathrm{~cm}$ (18).

Cell survival assay using standard cell culture dishes. Cell survival assay using standard cell culture dishes was performed as follows. For the gamma-ray irradiated cell survival assay, exponentially growing cultured cells were irradiated as described above and plated onto P-60 cell culture dishes at a density designed to yield $\sim 100$ viable colony-forming cells per P-60 dish. For the heavy ion irradiated cell survival assay, $4 \mathrm{ml}$ culture medium containing 500 cells was plated onto each $\mathrm{P}-60$ dish $\sim 3 \mathrm{~h}$ prior to irradiation with $\mathrm{C}$ and $\mathrm{Fe}$ ions, as described above. All samples were incubated at $37^{\circ} \mathrm{C}$ for between 7 and 8 days, until cells had formed substantially sized colonies visible by eye. Surviving colonies were rinsed with $0.9 \% \mathrm{NaCl}$, fixed with $100 \%$ ethanol and stained using $0.1 \%$ crystal violet at room temperature. Each colony consisting of $>50$ cells was scored as a surviving colony. Cell survival curves were constructed using GraphPad Prism software (version 6; GraphPad Software, Inc., La Jolla, CA, USA) and linear quadratic regression. Three independent experiments were conducted. The D10 values, which represent doses required to achieve $10 \%$ survival, were obtained from each survival curve using GraphPad Prism software.

Cell survival assay using OptiCell culture chamber. The cell survival assay using OptiCell culture chambers was performed as described previously $(10,11)$. For the OptiCell survival assay following irradiation with SOBP C ions, $10 \mathrm{ml}$ of culture medium containing between 400 and 600 cells was added to each chamber $\sim 3 \mathrm{~h}$ prior to irradiation. In order to deliver a uniform cell killing effect to each cell line, 4 Gy was delivered to CHO10B2 and PADR9 cells, 2 Gy was delivered to V3 cells, and 3 Gy was delivered to 51D1 cells at a depth of $0 \mathrm{~cm}$. Immediately following irradiation, all samples were incubated for between 7 and 8 days as described above. Each colony consisting of $>50$ cells was scored as a surviving colony. At least two independent experiments were performed using each cell line. The SOBP slope values, which represent the isobiological cell killing effect of SOBP irradiation, were calculated as a linear regression with survival fraction data at depths of between 8 and $14 \mathrm{~cm}$. The proximal and distal SOBP regions were defined as between 8 and $11 \mathrm{~cm}$, and 11 and $14 \mathrm{~cm}$, respectively, and used in the comparison of cell killing effects.

Statistical analysis. All data were analyzed using GraphPad Prism software. Values are presented as the mean \pm standard error of the means. Statistical comparison was performed using an unpaired two tailed $t$-test. $\mathrm{P}<0.05$ was considered to indicate a statistically significant difference.

\section{Results}

Cell survival in low and high LET-irradiated DNA repair deficient-CHO cell lines. Cell survival in DNA repair 
Table I. RBE values calculated from $\mathrm{D}_{10}$ values for $\mathrm{CHO}$ wild type and DNA repair deficient mutants.

Cell line, RBE value

\begin{tabular}{lcllc}
\cline { 2 - 5 } Heavy ion & CHO10B2 & V3 & 51D1 & PADR9 \\
\hline $\mathrm{C}$ ions $(13 \mathrm{keV} / \mu \mathrm{m})$ & 1.54 & 1.37 & 1.73 & 1.38 \\
$\mathrm{C}$ ions $(70 \mathrm{keV} / \mu \mathrm{m})$ & 2.76 & 1.5 & 2.5 & 2.66 \\
$\mathrm{Fe}$ ions $(200 \mathrm{keV} / \mu \mathrm{m})$ & 2.93 & 1.19 & 2.31 & 2.66
\end{tabular}

RBE, relative biological effectiveness; CHO, Chinese hamster ovary.

deficient-CHO cell lines was evaluated to assess the response to gamma-rays, $\mathrm{C}$ ions (LET, 13 and $70 \mathrm{keV} / \mu \mathrm{m}$ ) and $\mathrm{Fe}$ ions (LET, $200 \mathrm{keV} / \mu \mathrm{m}$; Fig. 1). CHO10B2 and PADR9 cells were observed to be radioresistant cells. The survival curves following gamma-ray irradiation were linear quadratic. Although CHO10B2 and PADR9 exhibited moderate sensitivity to $\mathrm{C}$ ions (LET, $13 \mathrm{keV} / \mu \mathrm{m}$ ), they exhibited increased sensitivity to $\mathrm{C}$ ions (LET, $70 \mathrm{keV} / \mu \mathrm{m}$ ) and Fe ions (LET, $200 \mathrm{keV} / \mu \mathrm{m}$ ) compared with gamma-rays. At the high LET radiation exposure, the cell survival curves of CHO10B2 and PADR9 cells were exponential. V3 cells were the most radiosensitive cells among tested cell lines and exhibited exponential cell survival curves. The radiosensitivities of V3 cells were similar for the low LET and high LET radiation. 51D1 cells exhibited intermediate radiosensitivity compared with the four cell lines. 51D1 cells exhibited relatively increased radiosensitivity to $\mathrm{C}$ ions (LET, $13 \mathrm{keV} / \mu \mathrm{m}$ ) compared with the other cells.

In order to quantitatively evaluate the responses, the relative biological effectiveness (RBE) values of the $290 \mathrm{MeV} / \mathrm{n}$ $\mathrm{C}$ ions (LET, 13 and $70 \mathrm{keV} / \mu \mathrm{m}$ ) and $500 \mathrm{MeV} / \mathrm{n} \mathrm{Fe}$ ions were calculated based on the D10 values (Table I). Gamma-rays were adopted as the standard radiation. The $\mathrm{C}$ (LET, 13 and $70 \mathrm{keV} / \mu \mathrm{m})$ and $\mathrm{Fe}$ ions exhibited an RBE of 1.54, 2.76 and
2.93 in CHO10B2 cells, 1.37, 1.50 and 1.19 in V3 cells, 1.73, 2.50 and 2.31 in 51D1 cells, and 1.38, 2.66 and 2.66 in PADR9 cells, respectively. The cell lines exhibited similar radiosensitivity, in terms of RBE values, following irradiation with $70 \mathrm{keV} / \mu \mathrm{m} \mathrm{C}$ ions compared with irradiation with the $\mathrm{Fe}$ ions.

Cell survival following irradiation with SOBP $C$ ions compared with depth. The cell survival assay using the OptiCell $^{\mathrm{TM}}$ culture system following irradiation with SOBP $\mathrm{C}$ ions was performed in $\mathrm{CHO} 10 \mathrm{~B} 2, \mathrm{~V} 3,51 \mathrm{D} 1$ and PADR9 cells. SOBP C ions were delivered at depths of between 8 and $14 \mathrm{~cm}$ (Fig. 2). At a depth of $1.4 \mathrm{~cm}$, the survival fraction was 0.30 for CHO10B2, 0.37 for V3, 0.21 for $51 \mathrm{D} 1$ and 0.43 for PADR9. As observed in all cell lines, the survival fraction decreased gradually from $1.4 \mathrm{~cm}$ to a depth of $8 \mathrm{~cm}$ and rapidly increased at a depth of $14 \mathrm{~cm}$. In the $\mathrm{SOBP}$ region, the minimum survival fraction was 0.050 for $\mathrm{CHO} 10 \mathrm{~B} 2,0.140$ for V3, 0.048 for 51D1 and 0.077 for PADR9. When compared with the entrance region, the SOBP region exhibited between a 5 - and 6-fold increase in cell death in the CHO10B2 $(\mathrm{P}=0.002)$ and PADR9 $(\mathrm{P}=0.037)$ cells, and an 2 .7-fold increase in cell death in the V3 $(\mathrm{P}=0.023)$ and 51D1 cells $(\mathrm{P}=0.001$; Fig. 3).

SOBP slope values in the SOBP region. Comparing the profile of the SOBP region survival fractions of $\mathrm{CHO} 10 \mathrm{~B} 2$ and PADR9 cells with those of V3 and 51D1 cells, the V3 and 51D1 cells exhibited increased survival at the distal SOBP region. In order to evaluate the cytotoxic efficiency of the SOBP region, SOBP slope values were calculated (Fig. 4). The values of each cell line were 0.017 (CHO10B2), 0.059 (V3), 0.046 (51D1) and $\sim 0$ (PADR9). SOBP slope values nearing 0 suggest isobiological cell death within the SOBP region. Only the V3 cells exhibited a statistically significant increase in cell death to proximal SOBP compared with distal SOBP $(\mathrm{P}=0.027$; Fig. 4B). 51D1 cells exhibited a marked trend of increased radioresistance to distal SOBP compared with proximal SOBP ( $\mathrm{P}=0.052$; Fig. 4C). CHO10B2 ( $\mathrm{P}=0.947$; Fig. 4A) and PADR9 $(\mathrm{P}=0.906$; Fig. 4D) did not exhibit significant differences between proximal and distal SOBP cytotoxicity.
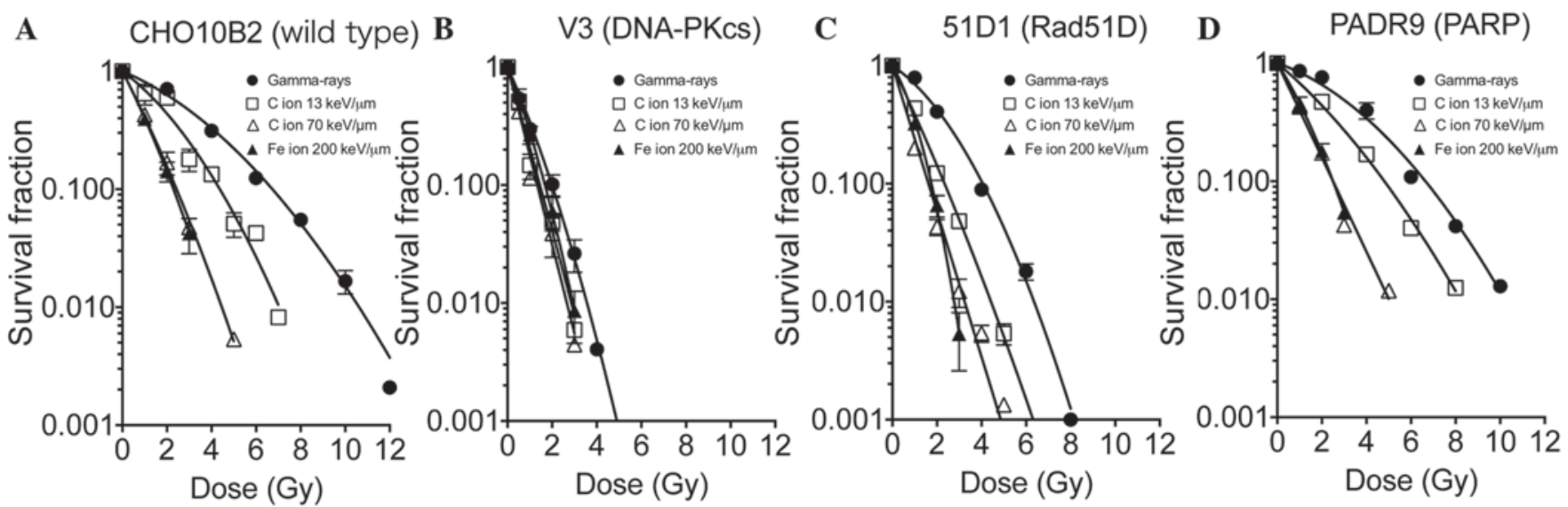

Figure 1. Cell survival in DNA repair deficient-CHO cell lines. The survival fractions of (A) CHO10B2, (B) V3, (C) 51D1 and (D) PADR9 cells, following irradiation with gamma-rays, C ions (LET, 13 and $70 \mathrm{keV} / \mu \mathrm{m}$ ) and Fe ions (LET, $200 \mathrm{keV} / \mu \mathrm{m}$ ), were determined using colony formation assays. Closed circles indicate gamma-rays, open squares indicate $\mathrm{C}$ ions LET $13 \mathrm{keV} / \mu \mathrm{m}$, open triangles indicate $\mathrm{C}$ ions LET $70 \mathrm{keV} / \mu \mathrm{m}$, and closed triangles indicate Fe ions $200 \mathrm{keV} / \mu \mathrm{m}$. Values are presented as the mean \pm standard error of the mean of three independent experiments. CHO, Chinese hamster ovary; LET, linear energy transfer; DNA-PKcs, protein kinase DNA-activated catalytic polypeptide; Rad51D, RAD51 paralog D; PARP, poly(ADP-ribose) polymerase. 
A

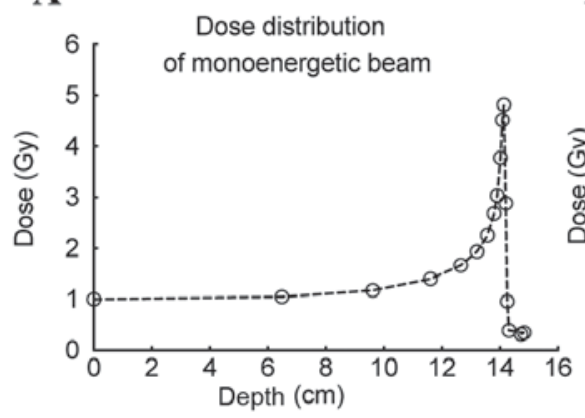

B

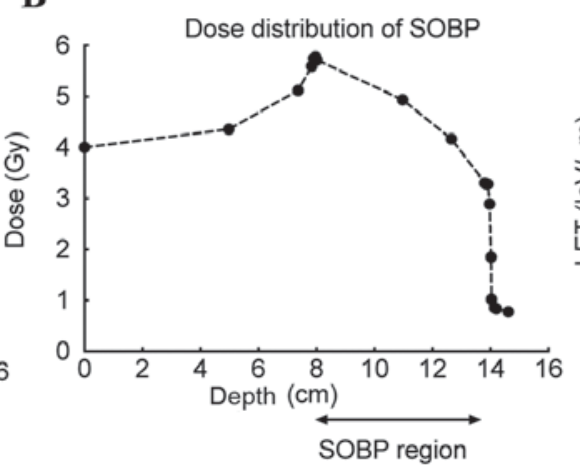

C

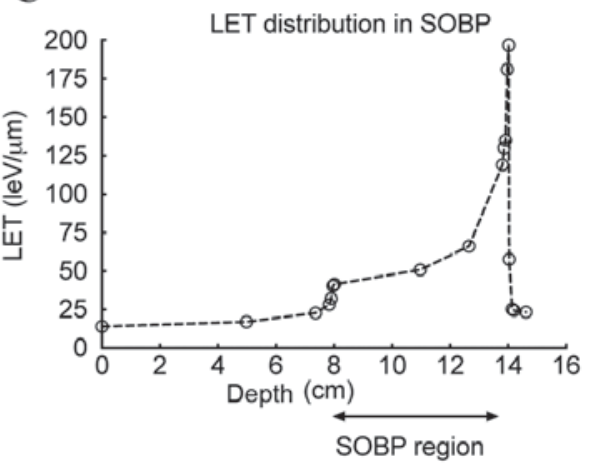

Figure 2. Dose and LET distribution of $\mathrm{C}$ beam path. Dose distribution values for the (A) monoenergetic and (B) SOBP C ions, and (C) LET distribution values for the SOBP C ions, were calculated at increasing depth. The SOBP region was defined as a depth of between 8 and $14 \mathrm{~cm}$. LET, linear energy transfer; SOBP, spread-out Bragg peak.

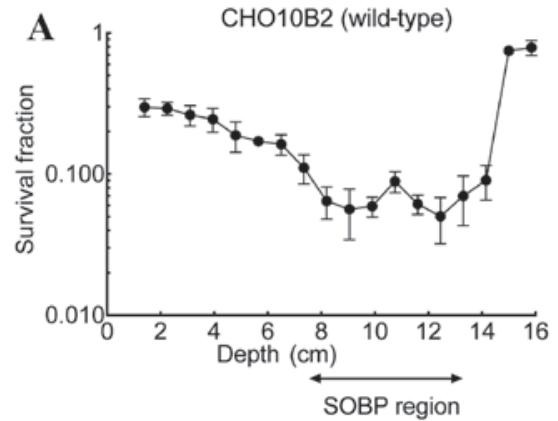

C

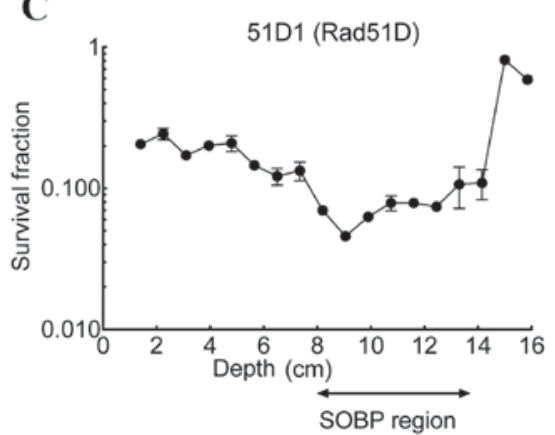

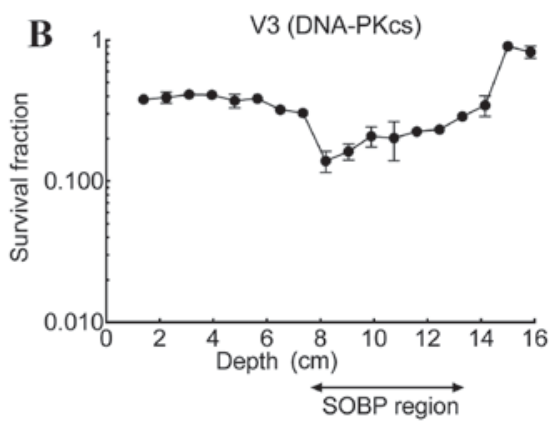

D

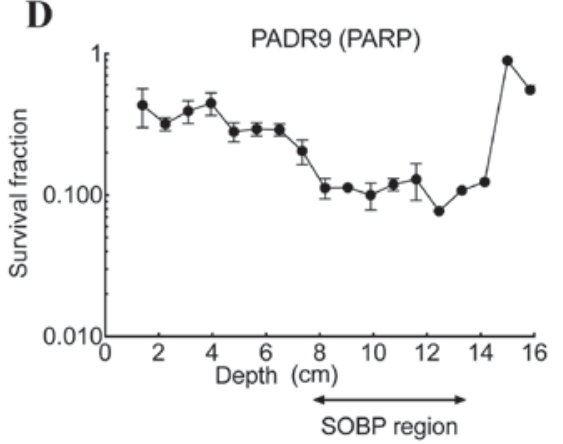

Figure 3. The survival fractions of (A) CHO10B2, (B) V3, (C) 51D1 and (D) PADR9 cells irradiated with SOBP C ions were determined using OptiCell ${ }^{\mathrm{TM}}$ colony formation assays at varying depths. Values are presented as the mean \pm standard error of the mean of at least two independent experiments. The SOBP region was defined as a depth of between 8 and $14 \mathrm{~cm}$. CHO, Chinese hamster ovary; SOBP, spread-out Bragg peak; DNA-PKcs, protein kinase DNA-activated catalytic polypeptide; Rad51D, RAD51 paralog D; PARP, poly(ADP-ribose) polymerase.
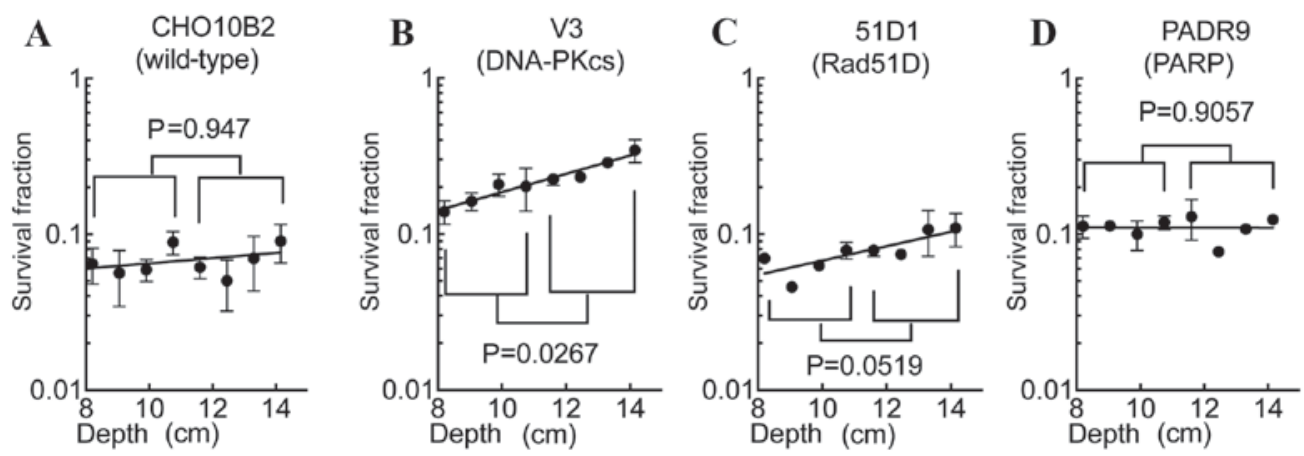

Figure 4. SOBP slope values of the cell survival curves in the SOBP region. The slope values of (A) CHO10B2, (B) V3, (C) 51D1 and (D) PADR9 cells irradiated with SOBP C ions were calculated from the survival fraction data from the OptiCell ${ }^{\mathrm{TM}}$ culture system at depths of between 8 and $14 \mathrm{~cm}$. Values are presented as the mean \pm standard error of the mean from at least two independent experiments. CHO, Chinese hamster ovary; SOBP, spread-out Bragg peak; DNA-PKcs, protein kinase DNA-activated catalytic polypeptide; Rad51D, RAD51 paralog D; PARP, poly(ADP-ribose) polymerase. 


\section{Discussion}

In the present study, the biological effect of irradiation with the SOBP beam region of $\mathrm{C}$ ions was assessed using the OptiCell $^{\mathrm{TM}}$ culture system, as reported previously $(10,11)$, and used to construct a three-dimensional geometric in vitro experiment. The results of the present study demonstrated that a $6 \mathrm{~cm}$ wide SOBP C beam consists of various monoenergetic Bragg peak beams, which cause rapid build-up of radiation dosage at a depth of $8 \mathrm{~cm}$, a gradual decrease until the proximal boundary and a rapid decrease at $14 \mathrm{~cm}$. Conversely, LET gradually increases up to a depth of $14 \mathrm{~cm}$. The combination of these dosages and LET distributions enables the isobiological killing of cells within the SOBP region. However, the LET distribution in the SOBP region is wider compared with monoenergetic beams (5). The biological effects from irradiation with monoenergetic ions and SOBP with the identical average LET were distinct (5). Therefore, monoenergetic ions cannot be used to estimate the biological effects of irradiation with SOBP with identical average LET values.

LET-dependent radiosensitivities were studied in wild-type and DNA repair deficient-CHO cell lines in the present study. Following the construction of cell survival curves, wild-type and DNA repair deficient-cell lines exhibited distinct biological effects when exposed to high LET radiation. RBE values were demonstrated to increase as LET increases in wild-type cells, while this association between LET level and $\mathrm{RBE}$ value was not observed in V3 cells. It was confirmed that radiosensitivity is dose-dependent in NHEJ-deficient cells but not LET-dependent, as was previously demonstrated $(17,19)$. Therefore, disruption of NHEJ repair may not be the optimum strategy for the enhancement of tumor control using high LET radiation. The 51D1 cells exhibited increased radiosensitivity to irradiation with $13 \mathrm{keV} / \mu \mathrm{m} \mathrm{C}$ ions, which represents the entrance region of the $\mathrm{C}$ ion beam. $\mathrm{C}$ ions with LET of $13 \mathrm{keV} / \mu \mathrm{m}$ may be exposed to the normal tissues that surround tumor tissues. Unless tumors are selectively targeted by HR inhibitors, it may cause certain side effects in normal tissues. Conversely, as PADR9 cells exhibited a shift in sensitivity to high LET radiation from 13 to $70 \mathrm{keV} / \mu \mathrm{m} \mathrm{C}$ ions, elevated side effects in normal tissues from PARP inhibition may be limited. This high LET-specific sensitivity is an attractive target for $\mathrm{C}$ ion radiotherapy. In particular, PARP is a repair protein associated with single strand break repair $(8,9)$. It has also been reported that PARP may serve a role in DSB repair (20). As high LET radiation produces complex types of DNA damage, which are a mixture of single strand break and DSB, PARP may be a promising therapeutic target (21-23). The results of the present study appear to be in accordance with the PARP inhibitor-induced sensitization with high LET radiation (24), and indicate PARP inhibition may be a potential target for heavy ion radiation therapy.

The SOBP beam was originally designed to achieve uniform cytotoxicity in human salivary gland (HSG) cells (25). In the present study, $\mathrm{CHO}$ wild-type cells exhibited similar isobiological cell killing effects within the SOBP region compared with HSG cells (25). The SOBP region had distinct impacts on each cell line and the SOBP slopes between depths of 8 and $14 \mathrm{~cm}$ were calculated. Compared with the slope value of the wild-type cells, the decreased slope values of the other cell lines demonstrated that the cells were sensitive to radiation in an LET-dependent manner. These results indicated that DNA repair deficiency selectively sensitizes cells to high LET radiation. The SOBP slope value of PADR9 cells was the lowest $(\sim 0)$ followed by that of CHO10B2 (0.017), 51D1 (0.046) and V3 (0.059) cells (Fig. 4). The order of slope values and differences in RBE values among the cell lines were associated. As hypothesized following the construction of cell survival curves, V3 cells exhibited the highest slope value among the cell lines due to their low RBE value following irradiation to high LET radiation. HR-deficient 51D1 cells exhibited increased slope values compared with the wild-type cells. Multiple reports suggested that damage produced by high LET radiation is repaired by HR with partial suppression of the NHEJ signaling pathway $(6,7)$. The results of the present study suggested that inhibiting NHEJ or HR may lead to non-uniform cytotoxicity within the $\mathrm{C}$ ion $6 \mathrm{~cm}$ SOBP region. Although disruptions of these signaling pathways will result in increased cytotoxicity in the SOBP region, the current SOBP design obtained from the HSG cell results cannot be directly applied clinically to radiotherapy. Conversely, PADR9 cells exhibited isobiological cell killing effects within the SOBP region. The results of the present study suggest that PARP is an effective inhibitory target to complement radiotherapy.

In conclusion, the radiosensitivity of DNA repair deficient-CHO cell lines to high and low LET was investigated, and the isobiological cell killing effects in the SOBP region of the radiation beam were evaluated using an OptiCell system. PARP inhibition was identified to potentially be an optimal target to complement radiotherapy, and the results of the present study may contribute to the development of more effective heavy ion radiation therapies.

\section{Acknowledgements}

The authors of the present study would like to thank Mr. T. Inoue and Mr. Y. Hao (The University of Tokyo, Tokyo, Japan) for technical assistance, and support from National Institute of Radiological Sciences-HIMAC. The present study was partially supported by the Dr Akiko M. Ueno Radiobiology Fund, the Japan Ministry of Education, Culture, Sports, Science and Technology Grants-in-Aid for Scientific Research on Innovative Areas (grant no. 15H05935) and the Japan Society for the Promotion of Science research fellowship (grant no. 15J09331).

\section{References}

1. Durante M and Loeffler JS: Charged particles in radiation oncology. Nat Rev Clin Oncol 7: 37-43, 2010.

2. Marx V: Cancer treatment: Sharp shooters. Nature 508: 133-138, 2014.

3. Okayasu R: Repair of DNA damage induced by accelerated heavy ions-A mini review. Int J Cancer 130: 991-1000, 2012.

4. Hirayama R, Furusawa Y, Fukawa T and Ando K: Repair Kinetics of DNA-DSB induced by X-rays or C Ions under oxic and hypoxic conditions. J Radiat Res 46: 325-332, 2005.

5. Belli M, Bettega D, Calzolari P, Cherubini R, Cuttone G, Durante M, Esposito G, Furusawa Y, Gerardi S, Gialanella G, et al: Effectiveness of monoenergetic and spread-out bragg peak carbon-ions for inactivation of various normal and tumour human cell lines. J Radiat Res 49: 597-607, 2008. 
6. Okayasu R, Okada M, Okabe A, Noguchi M, Takakura K and Takahashi S: Repair of DNA damage induced by accelerated heavy ions in mammalian cells proficient and deficient in the non-homologous end-joining pathway. Radiat Res 165: 59-67, 2006.

7. Yajima H, Fujisawa H, Nakajima NI, Hirakawa H, Jeggo PA Okayasu R and Fujimori A: The complexity of DNA double strand breaks is a critical factor enhancing end-resection. DNA Repair (Amst) 12: 936-946, 2013.

8. Benjamin RC and Gill DM: Poly(ADP-ribose) synthesis in vitro programmed by damaged DNA. A comparison of DNA molecules containing different types of strand breaks. J Biol Chem 255: 10502-10508, 1980.

9. Benjamin RC and Gill DM: ADP-ribosylation in mammalian cell ghosts. Dependence of poly(ADP-ribose) synthesis on strand breakage in DNA. J Biol Chem 255: 10493-10501, 1980.

10. Genet SC, Maeda J, Fujisawa H, Yurkon CR, Fujii Y, Romero AM, Genik PC, Fujimori A, Kitamura H and Kato TA: Comparison of cellular lethality in DNA repair-proficient or -deficient cell lines resulting from exposure to $70 \mathrm{MeV} / \mathrm{n}$ protons or $290 \mathrm{MeV} / \mathrm{n} \mathrm{C}$ ions. Oncol Rep 28: 1591-1596, 2012.

11. Fujisawa H, Genik PC, Kitamura H, Fujimori A, Uesaka M and Kato TA: Comparison of human chordoma cell-kill for 290 $\mathrm{MeV} / \mathrm{n} \mathrm{C}$ ions versus $70 \mathrm{MeV}$ protons in vitro. Radiat Oncol 8 : 91, 2013.

12. Whitmore GF, Varghese AJ and Gulyas S: Cell cycle responses of two X-ray sensitive mutants defective in DNA repair. Int J Radiat Biol 56: 657-665, 1989.

13. MacLaren RA, Witmer MV, Richardson E and Stamato TD Isolation of Chinese hamster ovary cells with reduced poly(ADP-ribose) polymerase activity. Mutat Res 231: 265-274, 1990.

14. Witmer MV, Aboul-Ela N, Jacobson MK and Stamato TD: Increased sensitivity to DNA-alkylating agents in $\mathrm{CHO}$ mutants with decreased poly(ADP-ribose) polymerase activity. Mutat Res 314: 249-260, 1994

15. Hinz JM, Tebbs RS, Wilson PF, Nham PB, Salazar EP, Nagasawa H, Urbin SS, Bedford JS and Thompson LH: Repression of mutagenesis by Rad51D-mediated homologous recombination. Nucleic Acids Res 34: 1358-1368, 2006.
16. Sunada S, Fujisawa H, Cartwright IM, Maeda J, Brents CA, Mizuno K,Aizawa Y,Kato TA and Uesaka M: Monoglucosyl-rutin as a potential radioprotector in mammalian cells. Mol Med Rep 10: 10-14, 2014.

17. Mcmillan DD, Maeda J, Bell JJ, Genet MD, Phoonswadi G, Mann KA, Kraft SL, Kitamura H, Fujimori A, Yoshii Y, et al: Validation of $64 \mathrm{Cu}$-ATSM damaging DNA via high-LET Auger electron emission. J Radiat Res 56: 784-791, 2015.

18. Maeda J, Cartwright IM, Haskins JS, Fujii Y, Fujisawa H, Hirakawa H, Uesaka M, Kitamura H, Fujimori A, Thamm DH and Kato TA: Relative biological effectiveness in canine osteosarcoma cells irradiated with accelerated charged particles. Oncol Lett 12: 1597-1601, 2016.

19. Weyrather WK, Ritter S, Scholz M and Kraft G: RBE for carbon track-segment irradiation in cell lines of differing repair capacity. Int J Radiat Biol 75: 1357-1364, 1999.

20. Beck C, Robert I, Reina-San-Martin B, Schreiber V and Dantzer F: Poly(ADP-ribose) polymerases in double-strand break repair: Focus on PARP1, PARP2 and PARP3. Exp Cell Res 329: 18-25, 2014.

21. Urushibara A, Shikazono N, O'Neill P, Fujii K, Wada S and Yokoya A: LET dependence of the yield of single-, double-strand breaks and base lesions in fully hydrated plasmid DNA films by 4He(2+) ion irradiation. Int J Radiat Biol 84: 23-33, 2008.

22. Taucher-Scholz G and Kraft G: Influence of radiation quality on the yield of DNA strand breaks in SV40 DNA irradiated in solution. Radiat Res 151: 595-604, 1999.

23. Taucher-Scholz G, Stanton JA, Schneider M and Kraft G: Induction of DNA breaks in SV40 by heavy ions. Adv Space Res 12: 73-80, 1992.

24. Hirai T, Shirai H, Fujimori H, Okayasu R, Sasai K and Masutani M: Radiosensitization effect of poly(ADP-ribose) polymerase inhibition in cells exposed to low and high liner energy transfer radiation. Cancer Sci 103: 1045-1050, 2012.

25. Kagawa K, Murakami M, Hishikawa Y, Abe M, Akagi T, Yanou T, Kagiya G, Furusawa Y, Ando K, Nojima K, et al: Preclinical biological assessment of proton and carbon ion beams at Hyogo ion beam medical center. Int J Radiat Oncol Biol Phys 54: 928-938, 2002. 